\title{
The New Oral Anticoagulants (NOACs) Between Prevention of Systemic Thromboembolism and Bleeding Procedures in the Dental Office: Review of Literature and Case Report
} Andrada Soancă ${ }^{3}$, Radu Septimiu Câmpian¹, Bianca Adina Boșca ${ }^{4}$, Alina Simona Șovrea ${ }^{4}$, Anca Ștefania Mesaros ${ }^{5}$

ISSN: 2637-7764

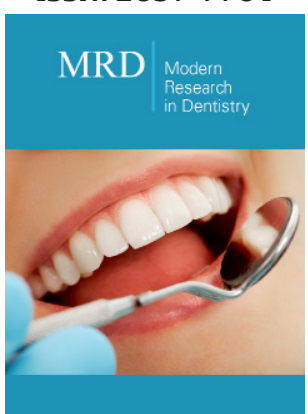

*Corresponding author: Aranka Ilea, Department of oral rehabilitation, Romania Vlad Andrei, Rezident doctor in periodontology, Romania

Submission: 眥 March 25, 2019

Published: 陋April 23, 2019

Volume 4 - Issue 1

How to cite this article: Ilea A, Andrei V, Băbțan AM, Petrescu NB, Soancă A, Câmpian RS, Boșca BA, Șovrea AS, Mesaros AȘ. The New Oral Anticoagulants (NOACs) Between Prevention of Systemic Thromboembolism and Bleeding Procedures in the Dental Office: Review of Literature and Case Report. Mod Res Dent. 4(1). MRD.000576.2019.

DOI: 10.31031/MRD.2019.04.000576

Copyright@ Aranka Ilea and Vlad Andrei, This article is distributed under the terms of the Creative Commons Attribution 4.0 International License, which permits unrestricted use and redistribution provided that the original author and source are credited.
1"Iuliu Hațieganu" University of Medicine and Pharmacy Cluj-Napoca; Department of Oral Rehabilitation, Oral Health and Dental Office Management; Faculty of Dentistry, Romania

${ }^{2}$ Rezident doctor in Periodontology, Clinical County Hospital of Târgu Mureș, Romania

3"Iuliu Haţieganu" University of Medicine and Pharmacy Cluj-Napoca, Department of Periodontology, Faculty of Dentistry, Romania

4"Iuliu Haţieganu" University of Medicine and Pharmacy Cluj-Napoca, Department of Histology, Faculty of Medicine, Romania

5"Iuliu Hațieganu" University of Medicine and Pharmacy Cluj-Napoca, Department of Dental Propedeutics and Esthetics, Faculty of Dentistry, Romania

\begin{abstract}
There is insufficient data on the use of NOACs during bleeding procedures in the dental office versus old oral anticoagulants. The current therapeutic indications are mostly based on the pharmacodynamics or on small cohort studies. Data from the literature has been reviewed in this respect. A 62-year-old patient under treatment with Rivaroxaban complained of transitory pain in the posterior upper-right jaw. The extraction of second upper right molar was performed, followed by the suture of the socket. According to the therapeutic indications and the available literature on the subject, the administration of the anticoagulant was not ceased. In the following days, repeated bleeding episodes were reported in direct correlation with the timing of Rivaroxaban administration and dose reduction was required to stop post-operative bleeding.
\end{abstract}

Thus, the effect of NOACs could be unpredictable, as shown in the present case report. Therefore, further clinical research on the subject is needed.

Keywords: Anticoagulants; Apixaban; Dabigatran; Dentistry; Edoxaban; Rivaroxaban

\section{Introduction}

Anticoagulants are used for preventing or reducing blood clot formation and treatment of other related thrombotic disorders. Several types of anticoagulants are available, the old generation including, but not limited to Vitamin K antagonist, Unfractionated Heparin (UH) and Low Molecular Weight Heparins (LMWH) [1-3]. UH and LMWH have several drawbacks, such as: injectable administration and need to follow designated protocols assessing specific tests and dosage adjustments, whenever a bleeding oral intervention is required $[1,2,4]$. Vitamin $\mathrm{K}$ antagonists also have limitations because their absorption is influenced by the patient's diet [5]. The old generation of oral anticoagulants have a more global action over the coagulation factors, and a less specific action on certain coagulation factors. Thus, the introduction of the new oral anticoagulants (NOACs) in 2008 was well received, given their specific design of counteracting the limitations of traditional anticoagulants [2,4]. NOACs target specific coagulation factors, either thrombin (Factor IIa) or Factor Xa [6]. The first drugs introduced of this class were thrombin inhibitors, thrombin being the key enzyme in the coagulation cascade [6,7]. The representative of this class is Dabigatran, a drug mainly used for preventing systemic embolism and stroke in patients with valvular atrial fibrillation [7]. On the other hand, Factor Xa inhibitors directly bind to the site of Factor Xa, thus blocking the common pathway of coagulation [8]. The first approved drugs were Apixaban and Rivaroxaban, with the addition of a more recent entry, Edoxaban [6,9]. The main disadvantage of NOACs is that their activity is difficult to monitor [10]. 
Despite the many drawbacks, warfarin and heparin had the advantage of the follow up through specific tests, such as prothrombin time (PT), thromboplastin time (aPTT) and International Normalized Ratio (INR), respectively. These tests proved to be useful in certain situations, such as urgent surgery and, more important for the dentist, in situations when bleeding is expected to occur during dental procedures (Figure 1) [8]. However, there is poor or no correlation between NOACs drug concentration in the patient's plasma and the prolonged PT, INR and aPTT, which may lead to a high risk of error while interpreting the results of these examinations [10]. Useful for the evaluation of NOACs' efficiency would be the direct monitoring of the plasmatic concentrations of Factors Xa and IIa, which are currently unavailable to the dental practitioner (Figure 1).

Table 1: Eligible articles for the present literature review.

\begin{tabular}{|c|c|c|c|c|c|}
\hline Authors & Publication & Year & Type of Paper & $\begin{array}{l}\text { Number of } \\
\text { Patients or } \\
\text { Reviewed } \\
\text { Articles }\end{array}$ & NOACs \\
\hline Firriolo et al. [17] & $\begin{array}{c}\text { Oral Surg Oral Med Oral Pathol Oral } \\
\text { Radiol }\end{array}$ & 2012 & Discussion Paper & $\mathrm{N} / \mathrm{A}^{\dagger}$ & $\begin{array}{l}\text { Dabigatran } \\
\text { Rivaroxaban }\end{array}$ \\
\hline Romond et al. [27] & $\begin{array}{l}\text { Oral Surg Oral Med Oral Pathol Oral } \\
\text { Radiol Endod }\end{array}$ & 2013 & Case Report & 1 & Dabigatran \\
\hline Clayton et al. [28] & J Can Dent Assoc & 2013 & Literature review & $\mathrm{N} / \mathrm{A}$ & Dabigatran \\
\hline Breik et al. [18] & Aust Dent J & 2014 & Case series & 5 & Dabigatran \\
\hline $\begin{array}{l}\text { Gómez-Moreno et } \\
\text { al. [12] }\end{array}$ & Clin Oral Impl Res & 2016 & Cohort study & 57 & Rivaroxaban \\
\hline $\begin{array}{l}\text { Thean Alberghini } \\
\text { [4] }\end{array}$ & Aust Dent J & 2016 & Descriptive article & $\mathrm{N} / \mathrm{A}$ & $\begin{array}{c}\text { Dabigatran } \\
\text { Rivaroxaban } \\
\text { Apixaban }\end{array}$ \\
\hline $\begin{array}{l}\text { Costantinides et } \\
\text { al. [9] }\end{array}$ & BMC Oral Health & 2016 & Discussion Paper & $\mathrm{N} / \mathrm{A}$ & $\begin{array}{c}\text { Dabigatran } \\
\text { Rivaroxaban } \\
\text { Apixaban }\end{array}$ \\
\hline Johnston et al. [4] & Int J Oral Maxillofac Surg & 2016 & Literature review & 10 & $\begin{array}{c}\text { Dabigatran } \\
\text { Rivaroxaban } \\
\text { Apixaban }\end{array}$ \\
\hline Elad et al. [8] & Oral Dis & 2016 & Literature review & $\mathrm{N} / \mathrm{A}$ & $\begin{array}{c}\text { Dabigatran } \\
\text { Rivaroxaban } \\
\text { Apixaban } \\
\text { Edoxaban }\end{array}$ \\
\hline Hanken et al. [20] & Clin Oral Investig & 2016 & $\begin{array}{l}\text { Retrospective observa- } \\
\text { tional study }\end{array}$ & 52 & Rivaroxaban \\
\hline Kim et al. [30] & J Dent Anesth Pain Med & 2017 & Case report & 1 & Rivaroxaban \\
\hline Miclotte et al. [29] & Clin Oral Investig & 2017 & Cohort study & 52 & $\begin{array}{c}\text { Dabigatran } \\
\text { Rivaroxaban } \\
\text { Apixaban }\end{array}$ \\
\hline Curto et al. [9] & J Clin Exp Dent & 2017 & Literature review & $\mathrm{N} / \mathrm{A}$ & Edoxaban \\
\hline $\begin{array}{l}\text { Serrano-Sánchez et } \\
\text { al. [16] }\end{array}$ & Med Oral Patol Oral Cir Bucal & 2017 & Literature review & $\mathrm{N} / \mathrm{A}$ & $\begin{array}{c}\text { Dabigatran } \\
\text { Rivaroxaban } \\
\text { Apixaban } \\
\text { Edoxaban }\end{array}$ \\
\hline
\end{tabular}




\begin{tabular}{|c|c|c|c|c|c|}
\hline Nathwani et al. [21] & Br Dent J & 2017 & Literature review & N/A & $\begin{array}{c}\text { Dabigatran } \\
\text { Rivaroxaban } \\
\text { Apixaban }\end{array}$ \\
\hline Dézsi et al. [22] & Eur J Gen Pract & 2017 & Literature review & $\mathrm{N} / \mathrm{A}$ & $\begin{array}{c}\text { Dabigatran } \\
\text { Rivaroxaban } \\
\text { Apixaban } \\
\text { Edoxaban }\end{array}$ \\
\hline $\begin{array}{c}\text { Gómez-Moreno et } \\
\text { al. [7] }\end{array}$ & Clin Oral Impl Res & 2018 & Cohort study & 71 & Dabigatran \\
\hline Hassona et al. [26] & Oral Dis & 2018 & Case series & 10 & Dabigatran \\
\hline Lababidi et al. [23] & Int J Oral Maxillofac Surg & 2018 & $\begin{array}{l}\text { Retrospective con- } \\
\text { trolled cohort study }\end{array}$ & 128 & $\begin{array}{l}\text { Dabigatran } \\
\text { Rivaroxaban } \\
\text { Apixaban }\end{array}$ \\
\hline K Fortier et al. [31] & Gerodontology & 2018 & Literature review & $\mathrm{N} / \mathrm{A}$ & $\begin{array}{c}\text { Dabigatran } \\
\text { Rivaroxaban } \\
\text { Apixaban } \\
\text { Edoxaban }\end{array}$ \\
\hline
\end{tabular}

N/A-non-applicable/ not available information

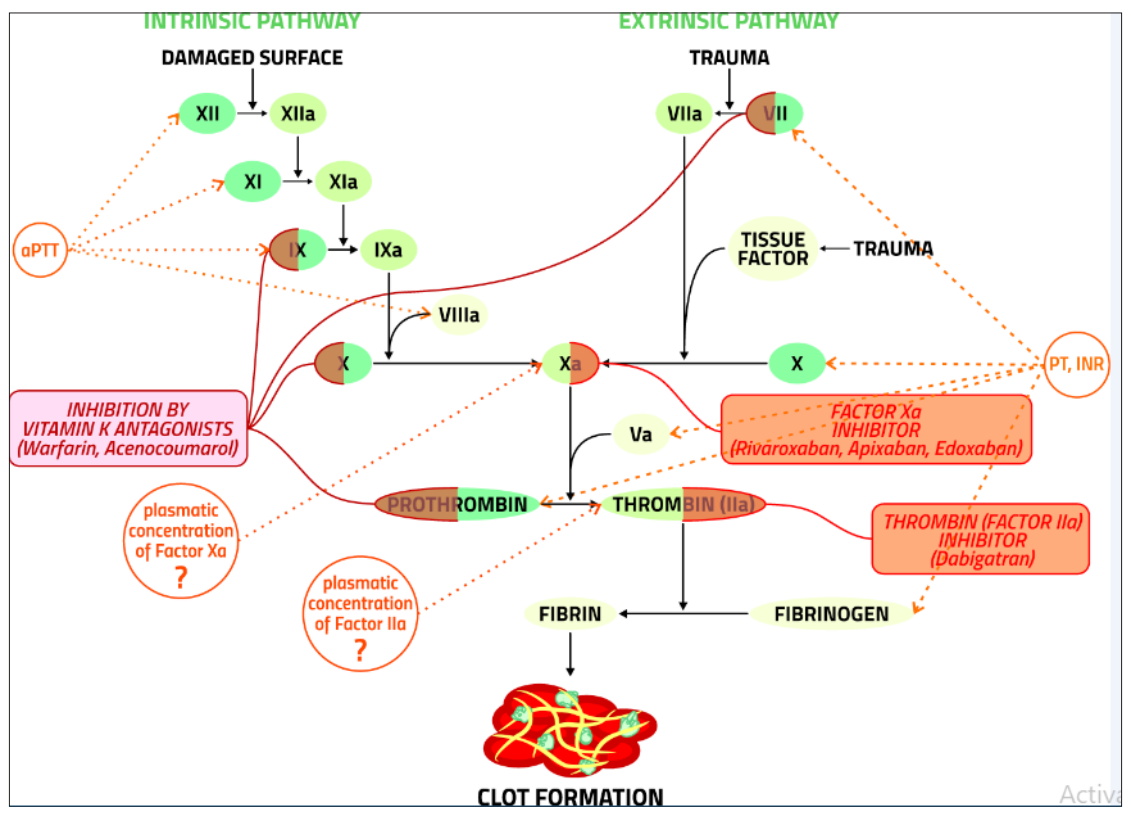

Figure 1: Oral anticoagulants' action in the coagulation cascade and their specific laboratory investigations.

Dental professionals should be able to identify the undergoing treatment such as oral anticoagulants as a possible risk factor for bleeding during the dental procedures. Thus, collaboration with the cardiologist and agreeing on the correct therapeutic attitude regarding the anticoagulant treatment is mandatory $[11,12]$.

Given the need for a predictable correlation between the risk of bleeding during dental treatments and the presence of one or several NOACs in the patient's regular medication, the medical literature does not provide reliable information. Protocols differ from one country and from one specialized association to another, with no clear algorithms for performing the bleeding procedures on patients under treatment with NOACs in the dental office. Thus, the primary aim of the present paper was to review the literature searching for protocols applied for patients treated with NOACs. Secondly, we present the case report of a patient under treatment with NOAC, in which the non-cessation of the anticoagulant therapy proved to result in post-operative bleeding complications. 


\section{Material and Methods}

The literature review of NOACs protocols in dentistry field started with a search of the existing literature and was conducted using medical databases (PubMed, Medscape, Cochrane). The keywords used for this purpose were: "Dabigatran", "Rivaroxaban", "Apixaban" and "Edoxaban", each with the association of the terms "dental surgery" or "dentistry". In the first step of the selection, the titles and abstracts of the obtained articles were reviewed. In order for an article to be considered eligible for the second step, several points had to be met. Only the articles written in English were included. Also, the articles had to investigate one or more of the four main NOACs (Dabigatran, Rivaroxaban, Apixaban or Edoxaban) and their correlations or implications in dentistry. Duplicate articles were removed and the absence of the abstract in the database was also considered exclusion criteria. In the second step, the full text was reviewed. For an article to be included in the present review, additional criteria had to be met. The full text had to be available for reading or purchasing. Furthermore, the articles had to include the protocols regarding the cessation or non-cessation of NOACs during dental treatments. Stating the existence of bleeding complications after therapy was not mandatory. The types of articles selected for the present study were: literature reviews, meta-analyses, cohort studies (prospective or retrospective), case reports or case series and discussion papers. Lastly, all of the articles had to have the listed references.

\section{Results}

The initial search of literature using the combination of keywords returned a total of 201 results. During the first step of the articles selection, 125 results were discarded because the different searches resulted in duplicate items. Moreover, out of the remaining 76 articles, 40 were either not in English or did not investigate the correlation between NOACs and dentistry or dental surgery. Thus, a number of 36 articles was considered as potentially eligible and underwent the full text review. A number of two articles did not have the full text available, as they were in press, and were eliminated. One of the articles was a speciality letter and was eliminated, as this type of publication was not considered for the present study and did not have any references cited in the text. Lastly, 13 of the articles did not investigate the correlation between cessation and non-cessation of NOACs and dentistry or dental surgery, thus being considered as not eligible. The full article selection process is presented in Figure 2.

Table 2: Eligible articles and the recommendations towards the cessation or non-cessation of NOACs. Reported postoperative complications.

\begin{tabular}{|c|c|c|c|}
\hline Authors & Cessation of the NOACs & Non-Cessation of the NOACs & Postoperative Complications \\
\hline Firriolo et al. [17] & Oral and maxillofacial surgical interventions & $\begin{array}{l}\text { Dental procedures that may cause } \\
\text { bleeding [incl. uncomplicated ex- } \\
\text { tractions] }\end{array}$ & $\mathrm{N} / \mathrm{A}^{\neq}$ \\
\hline Romond et al. [18] & Multiple surgical extractions [24h before surgery] & $\mathrm{N} / \mathrm{A}$ & Minor postoperative bleeding \\
\hline Clayton et al. [28] & $\begin{array}{l}\text { Multiple extractions Oral and maxillofacial surgical } \\
\text { interventions }\end{array}$ & $\mathrm{N} / \mathrm{A}$ & $\begin{array}{c}\text { Major postoperative bleeding } \\
\text { between } 3,8 \% \text { and } 5,1 \% \text { of the } \\
\text { cases }\end{array}$ \\
\hline Breik et al. [18] & $\begin{array}{l}\text { Multiple extractions Patients with comorbidities } \\
\text { [renal failure] Invasive surgical procedures }\end{array}$ & $\begin{array}{l}\text { Single extractions } \\
\text { Scaling } \\
\text { Restorations using a matrix band } \\
\text { Endodontic treatment }\end{array}$ & $\begin{array}{l}\text { Minor postoperative bleeding } \\
\text { in one of the cases } \\
\text { Major postoperative bleeding in } \\
\text { one of the cases }\end{array}$ \\
\hline $\begin{array}{l}\text { Gómez-Moreno et } \\
\text { al. [12] }\end{array}$ & N/A & Dental implants surgery & $\begin{array}{l}\text { Moderate postoperative bleed- } \\
\text { ing in 5,55\% of the cases }\end{array}$ \\
\hline $\begin{array}{l}\text { Thean D, Alberghini } \\
\text { M [4] }\end{array}$ & $\begin{array}{l}\text { Difficult or multiple extractions } \\
\text { Complex oral surgery }\end{array}$ & $\begin{array}{l}\text { Scaling and root planing } \\
\text { Restorative or endodontic treatment } \\
\text { Simple extractions } \\
\text { Surgery lasting }<45 \text { minutes }\end{array}$ & $\mathrm{N} / \mathrm{A}$ \\
\hline $\begin{array}{l}\text { Costantinides et } \\
\text { al. [9] }\end{array}$ & $\begin{array}{c}\text { Multiple extractions [ }>5 \text { teeth] } \\
\text { Oral and maxillofacial surgical interventions } \\
{[>45 \mathrm{~min}]} \\
\text { Head \& neck cancer } \\
\text { Patients with comorbidities }\end{array}$ & $\begin{array}{l}\text { Surgical procedures with low risk of } \\
\text { bleeding }\end{array}$ & $\mathrm{N} / \mathrm{A}$ \\
\hline Johnston et al. [3] & $\begin{array}{c}\text { Complicated extractions [ }>3 \text { teeth] } \\
\text { Complex or adjacent extractions } \\
\text { Flap rising procedures } \\
\text { Gingival recontouring } \\
\text { Biopsies }\end{array}$ & $\begin{array}{c}\text { Simple extractions }[1-3 \text { teeth }] \\
\text { Periodontal examination } \\
\text { Scaling and root planing } \\
\text { Restorations }\end{array}$ & $\mathrm{N} / \mathrm{A}$ \\
\hline
\end{tabular}




\begin{tabular}{|c|c|c|c|}
\hline Elad et al. [8] & $\begin{array}{c}\text { Extensive oral surgery } \\
\text { Simple oral surgery with a high risk of thrombo- } \\
\text { embolism }\end{array}$ & $\begin{array}{l}\text { Non-surgical procedures } \\
\text { Surgical procedures with low risk of } \\
\text { bleeding }\end{array}$ & $\mathrm{N} / \mathrm{A}$ \\
\hline H Hanken et al. [20] & $\mathrm{N} / \mathrm{A}$ & $\begin{array}{l}\text { Osteotomy } \\
\text { Dental implants }\end{array}$ & $\begin{array}{l}\text { Postoperative bleeding in } \\
11,5 \% \text { of the cases [1- } 6 \text { days] }\end{array}$ \\
\hline Kim et al. [30] & Dental implants & $\mathrm{N} / \mathrm{A}$ & $\begin{array}{l}\text { Delayed bleeding [ } 6 \text { days after } \\
\text { recommencing] }\end{array}$ \\
\hline Miclotte et al. [29] & Dental extractions & $\mathrm{N} / \mathrm{A}$ & $\begin{array}{l}\text { Minor or moderate postoper- } \\
\text { ative bleeding in } 46 \% \text { of the } \\
\text { cases }\end{array}$ \\
\hline Curto et al. [9] & Invasive surgical procedures & $\begin{array}{l}\text { Simple dental extraction } \\
\text { Minor oral surgery procedures }\end{array}$ & $\mathrm{N} / \mathrm{A}$ \\
\hline $\begin{array}{l}\text { Serrano Sánchez et } \\
\text { al. [25] }\end{array}$ & $\begin{array}{l}\text { Surgical procedures with moderate or high risk of } \\
\text { bleeding }\end{array}$ & $\begin{array}{c}\text { Surgical procedures with low risk of } \\
\text { bleeding }\end{array}$ & $\mathrm{N} / \mathrm{A}$ \\
\hline Nathwani et al. [21] & $\begin{array}{c}\text { Multiple extractions [>3 teeth] } \\
\text { Flap rising procedures } \\
\text { Dental implants surgery } \\
\text { Biopsies } \\
\text { Oral and maxillofacial surgical interventions }\end{array}$ & $\begin{array}{l}\text { Simple extractions }[<3 \text { teeth }] \\
\text { Incision and drainage of dental abscess }\end{array}$ & $\mathrm{N} / \mathrm{A}$ \\
\hline
\end{tabular}

N/A - non-applicable/ not available information

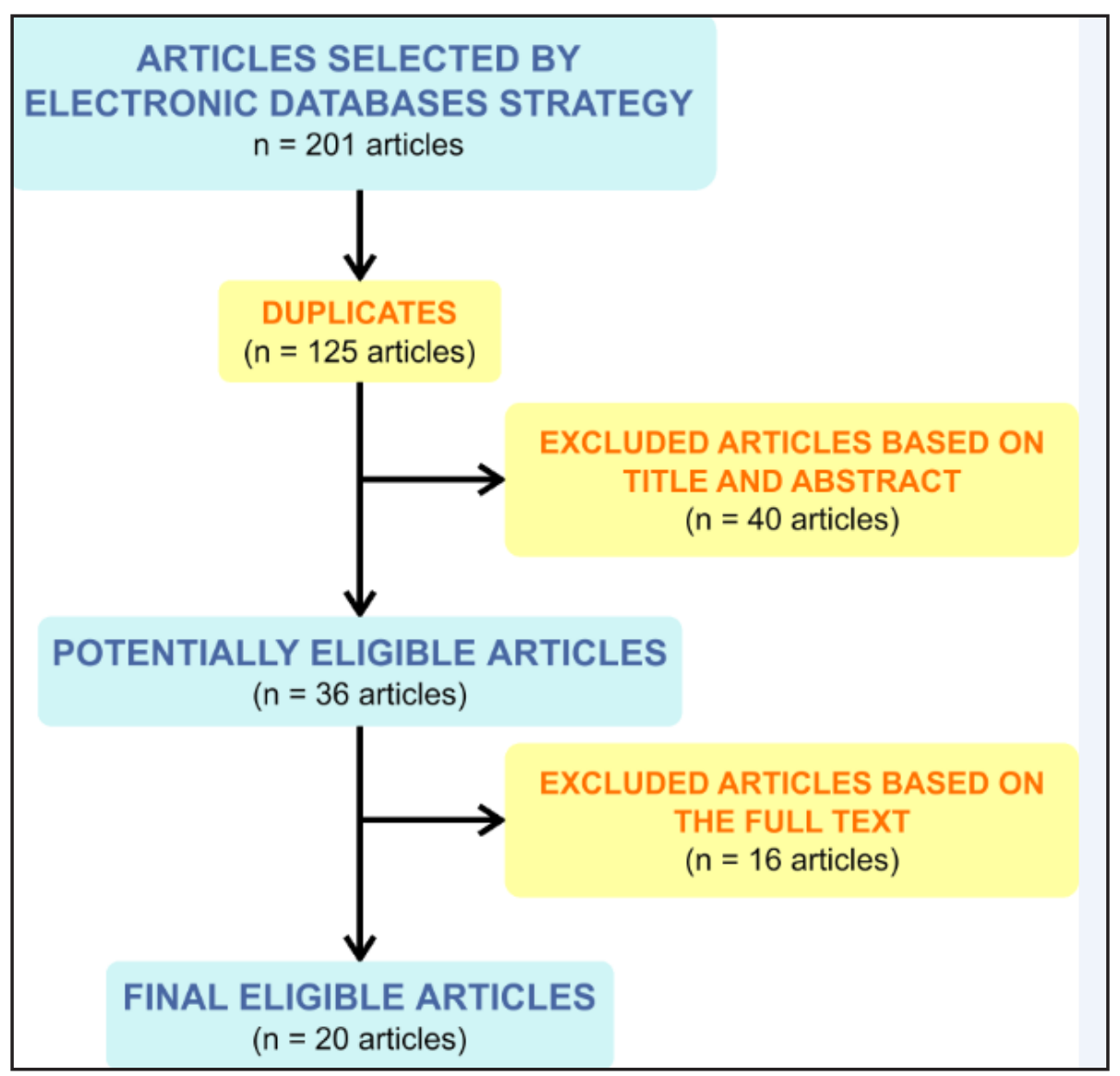

Figure 2: Article selection process. 
A total of 20 articles were considered to be eligible for the present literature review (Table 1). Out of the 20 articles, the most representative were the eight literature reviews; three articles were cohort studies, and two papers were case reports, case series and discussion papers; the descriptive articles, retrospective controlled cohort studies and retrospective observational studies only had one paper each. Moreover, out of the total number of 20 articles, five $(25 \%)$ used or recommended a protocol including only the cessation of NOACs, while only three of the final articles (15\%) used or recommended the non-cessation of NOACs. The remaining twelve eligible papers (60\%) gave specific recommendations for both cessation and non-cessation of NOACs. Furthermore, postoperative bleeding situations were mentioned in 10 of the final papers (Table 2). In a discussion paper from 2012, Firriolo FJ and Hupp WS stated that Dabigatran and Rivaroxaban did not seem to need cessation in the case of dental procedures that may cause slight bleeding, or in the case of most uncomplicated dental extractions [13]. This is applicable in patients with normal renal function and with no other risks of impaired haemostasis. However, the authors underlined the need for adjunctive local haemostatic measures, such as oxidised cellulose sponges, suturing and local pressure [13]. The same recommendation that simple extractions do not need the cessation of Dabigatran was stated in a case series published by Briek et al. [14] in 2014. Based on five cases treated with this drug, the authors stated that root scaling, dental restorations using a matrix band and endodontic treatments were also indicated without stopping the NOAC administration. However, the authors stated that in the case of multiple dental extractions and other invasive surgical procedures, the cessation of Dabigatran should be taken into consideration [14]. Similar observations were made by D Thean and M Alberghini in a descriptive article published in 2016 [6]. The authors stated that Dabigatran, Rivaroxaban and Apixaban do not need to be ceased in case of small bleeding surgery lasting less than 45 minutes [6,14]. Curto et al. stated in a literature review published in 2017 that simple extractions and minor oral surgery procedures do not require the cessation of Edoxaban, but it should be ceased before any invasive surgical procedures [9]. The differentiation between simple and complicated extractions was pointed out by S Johnston [4] based on 10 studies investigating Dabigatran, Rivaroxaban and Apixaban.

Simple extractions, which are limited to one to three teeth, do not require the cessation of NOACs; the same indication includes periodontal examinations, scaling and root planning or dental restorations. On the other hand, complicated extractions (more than three teeth), flap rising procedures, gingival re-contouring or biopsies should be preceded by the cessation of the anticoagulant therapy, in accordance with the cardiologist recommendation [4]. Furthermore, Gómez Moreno G et al. studied the appropriate approach regarding NOACs in relation with dental implants in two cohort studies published in 2016 and 2018 [7,15]. The first study investigated included 57 patients, all requiring dental implants, out of which 18 were being treated with Rivaroxaban for over six months. Following a protocol with no cessation of the anticoagulant, a total of $6.89 \%$ of the patients had minor bleeding complications after surgery, indicating that the decision regarding the NOAC administration was correct [15]. In the second cohort study, of a total of 71 patients requiring dental implants, 29 were being treated with Dabigatran for over 6 months, and the drug was not ceased during surgery. After the intervention, $5.55 \%$ of the patients had moderate bleeding, leading to the same conclusion that the protocol was correct [7].

The retrospective observational study was conducted by Hanken et al. [16] on 52 patients who underwent dental implants and osteotomies and were under continuous treatment with Rivaroxaban; two patients were under treatment with both Rivaroxaban and Acetylsalicylic acid. The postoperatory outcome was compared with 285 procedures performed on patients without any anticoagulant treatment. The postoperative bleeding rate in the NOAC group was $11.5 \%$, compared with less than $1 \%$ in the control group. However, the authors recommended the non-cessation of the drug, due to the easy management of the complications [16]. In a review published in 2017, S Nathwani and C Wanis concluded that treatment with Dabigatran, Rivaroxaban and Apixaban does not need to be cessed for simple extractions (less than three teeth) and for incisions and drainage of abscesses [17]. However, unlike G Gómez-Moreno et al., the authors indicated that dental implants should be preceded by the cessation of the NOACs $[7,9,17]$. The same was indicated for multiple extractions (more than three teeth), flap rising procedures, biopsies and oral and maxillofacial surgery [17]. The same approach was recommended by Dézsi et al. [18]: the cessation of Dabigatran, Rivaroxaban, Apixaban and Edoxaban for the extraction of more than 3 teeth, flap rising procedures, gingival re-contouring and biopsies, but non-cessation for the extraction of less than 3 teeth, the incision and drainage of dental abscesses, six-point periodontal examination, scaling and root planning or subgingival restorations [18]. In a retrospective controlled cohort study published in 2018, E Lababidi et al. investigated the occurrence of postoperative bleeding episodes in 59 patients on NOACs (Dabigatran, Rivaroxaban and Apixaban) and 69 patients treated with warfarin, with and without the anticoagulant cessation [19]. Following the intervention, minor bleeding episodes were seen in the non-cessation group, whereas no bleeding was recorded in the cessation group. Thus, the authors came to the conclusion that simple extractions of less than four teeth can be carried out without the cessation of NOACs [19]. The non-cessation of NOACs was recommended in a number of articles for procedures with a low risk of bleeding, a term defining simple extractions and common dental treatments (restorations, scaling and root planning, periodontal examination and endodontic treatment). This term was mentioned for the first time in a discussion paper published by F Costantinides et al. in 2016, referring to Dabigatran, Rivaroxaban and Apixaban [20]. The same indication appeared in a review published on the same year by Elad et al. [8]. After analysing the available data on the risk of bleeding after treatment with Dabigatran, Rivaroxaban, Apixaban and Edoxaban, the authors developed an algorithm for deciding pro or against the cessation of the anticoagulants [6]. 
The same conclusion was drawn by V Serrano-Sánchez in a literature review published in 2017, after analysing the existing data connecting the same four NOACs to dental surgery [21]. Lastly, the non-cessation of Dabigatran was concluded to be safe for procedures with a low risk of bleeding after a series of ten cases published by Hassona et al. in 2017 [22]. The cessation of NOACs for multiple extractions was indicated by Romond et al. [23] based on a case report published in 2013; a patient treated with Dabigatran had minor bleeding complications after the intervention [23]. These findings were confirmed by a literature review published on the same year by Clayton D et al. who added the indication of oral and maxillofacial surgical interventions to the cessation list [24]. Miclotte et al. [25] conducted a prospective cohort study on 52 patients and indicated the elimination of the morning dose of Dabigatran, Rivaroxaban and Apixaban prior to the intervention, even though the postoperative bleeding risk might be slightly higher [25]. Based on the case of a patient under treatment with Rivaroxaban who had multiple minor bleeding episodes several days after the dental implant surgery, $\mathrm{C}$ Kim et al. indicated the cessation of NOACs [26]. Recently, in a review published in 2018 by K Fortier et al., the cessation of Dabigatran, Rivaroxaban, Apixaban and Edoxaban was indicated in all dental surgery interventions, regardless of the high or low risk of bleeding [27-29].

\section{Practical case that invalidates the rules. What are the additional risk factors?}

A62-year-old malepatientwas referred to the DepartmentofOral Rehabilitation for a transitory pain that occurred during mastication in the posterior upper-right jaw. The patient's informed consent was obtained for the case report and photographic documentation, in accordance with the World Medical Association Declaration of Helsinki. The patient had significant associated general pathology: chronic atrial fibrillation, $3^{\text {rd }}$ degree hypertension, uncontrolled type II diabetes mellitus, mixt dyslipidaemia (both hypertriglyceridemia and hypercholesterolemia), obesity, liver steatosis, benign prostate hyperplasia with obstruction of the urinary bladder col and repeated urinary infections, and cervical spondylitis. Moreover, the patient's medical history included the surgical excision of a pigmented nodular baso-cellular carcinoma on the scalp. Heredocolateral antecedents on the maternal side revealed a case of stroke with unknown causes. Given the thromboembolic risk of the patient in relation with the general disease (atrial fibrillation), a regular treatment with Dabigatran (Pradaxa) was indicated; related to the anticoagulant treatment, the patient reported repeated gingival bleeding episodes. Therefore, the replacement of the drug with Rivaroxaban (Xarelto) was decided. The regular medication included Rivaroxaban (Xarelto, 20mg, once a day), along with a complex therapy for the various pathologies. The full therapeutic scheme included: Moxonidinum (Physiotens, $0.4 \mathrm{mg}$, once a day), Captoprilum (Captopril, 25mg, administered sublingually, when needed), a mixture of Perindoprilum and Indapamidum (Noliterax, 10/2.5mg, once a day), Bisoprololum (Concor, 5mg, twice a day), Metforminum (Siofor, 1g, twice a day), Atorvastatinum (Sortis, $20 \mathrm{mg}$, twice a day), Fenofibratum (Lipantil nano, 150mg, once a day) and Magnesia Orotas (Magnerot, $500 \mathrm{mg}$, once a day).
The exo-oral examination revealed the existence of several teleangiectatic surfaces in the mental, nasal, maseterin and zygomatic areas. Additionally, a scar was present on the right parietal area, at the site where the excision of the pigmented nodular baso-cellular carcinoma has been performed. The patient presented multiple simple carious lesions, inadequate prosthetic rehabilitations, as well as dental erosions and abrasions. The edentulous diagnosis in the maxillary was of Kennedy Class II subclass 1 . The patient also presented generalised medium chronic periodontitis and Miller Class 1 to 3 gingival recessions. The exam of the occlusion revealed active interferences in both propulsion and left laterality. Functionally, the mastication, aesthetics and self-sustaining of the dental apparatus were affected, but with a favourable long-term prognostic under correct treatment. The second upper right molar was causing difficulties in mastication and presented an incorrect prosthodontics rehabilitation. Upon periapical radiographic evaluation, an incorrect endodontic treatment, an incorrect coronal-radicular metallic restoration and the presence of an active marginal carious lesion were revealed. Part of the general treatment plan, the extraction of second upper right was decided.

The laboratory investigations revealed no pathologic values of the complete blood count, lipid panel, liver or renal functions tests. The coagulation investigations showed a slightly elevated prothrombin time (PT=20.6, reference values between 13 and 18 seconds) and an INR of 1.3. Based on the medical literature data and according to the laboratory investigations, the non-cessation of the Rivaroxaban was decided. Before the intervention, the patient's blood tension values and pulse were investigated, all the values being within normal range. The local-regional anaesthesia was performed by vestibular infiltration associated with a palatal foramen technique using Mepivacaine (Mepivastesin ${ }^{\mathrm{TM}}$, 3M ESPE). The extraction was non-traumatic, and the intraoperatory bleeding was not significant. The periapical pathologic tissue was removed from the socket with a curette and a non-resorbable suture was performed. The appropriate haemostasis occurred ten minutes after the extraction, and the patient was asked to keep a cotton gauge pressed on the postextractional alveolus for 30 minutes. On that evening, two to three hours after the administration of the usual Rivaroxaban dose $(20 \mathrm{mg})$, the bleeding at the extraction site began. The local haemostasis was attempted using a gauge with carbazochrome (Adrenostazin, Terapia), but a slight bleeding continued over the night and ceased only in the early morning. The following day, two to three hours after the administration of the daily dosage of Rivaroxaban (20mg), the bleeding reoccurred, but was easily managed using the supra alveolar gauge with carbazochrome (Adrenostazin, Terapia); however, the final haemostasis was obtained only when the NOAC dosage was reduced to $15 \mathrm{mg}$, according to the cardiologist's indication (Figure 3).

\section{Discussion}

The discussion on both old generation anticoagulants and NOACs seems to focus on what would be the correct approach: cessation or non-cessation of the therapy during oral surgery. The 
major concern is that the dental practitioner is unaware of the risks associated with the anticoagulant therapy. In 2016, S Johnston analysed 143 questionnaires delivered to medical practitioners regarding the recognition and correct approach towards NOACs. An increased number of practitioners (12-50\%) were unable to identify the drugs as being anticoagulants, while half of the respondents who recognized the drugs (55-58\%) were unable to take the appropriate decision about whether to continue with an invasive procedure [10]. The responsibility is divided between the cardiologist and the dental practitioner when it comes to managing a patient under treatment with anticoagulants. On one hand, the cardiologist must decide if the administration of the drug should be interrupted and the thromboembolic risk associated with this attitude must be assessed. In a retrospective study published by Shaw J et al. on a number of 190 patients with venous thromboembolic disease (VTE) requiring a temporary cessation of NOACs for invasive procedures, a rate of $1.05 \%$ (95\% CI, 0.29-3.8\%) of complication was determined by thromboembolism and a rate of $0.53 \%$ (95\% CI, 0.09-2.93\%) was related with major bleeding incidents.

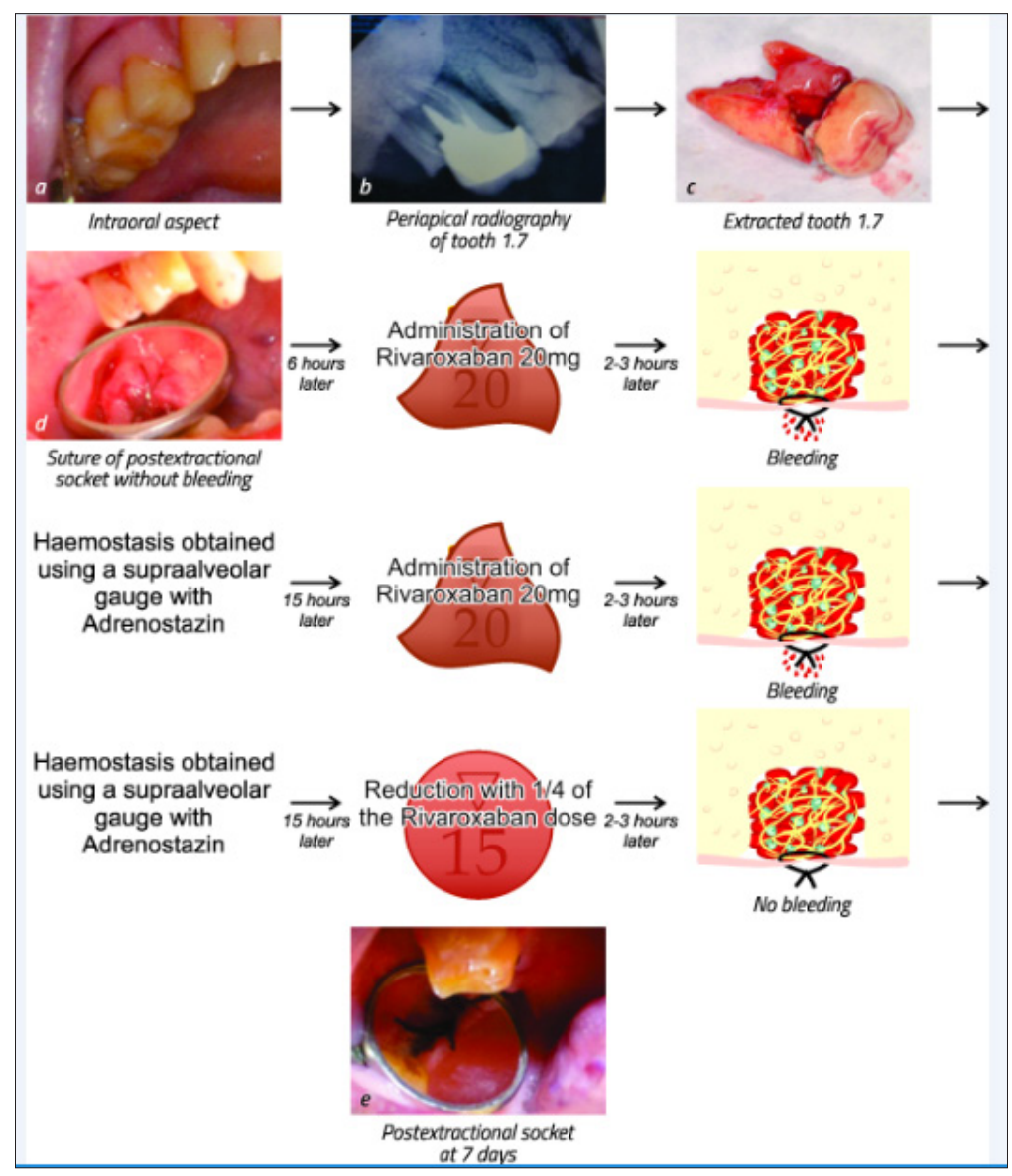

Figure 3: Case report timeline.

The values were comparable to those determined for warfarin by Clark et al. [30]. A meta-analysis was conducted by the same author, evaluating the thromboembolic and major bleeding risk of patients with atrial fibrillation in need of temporary interruption of the NOACs. The obtained values were $0.41 \%$ (95\% CI 0.29- 0.54) for thromboembolic incidents and $1.81 \%$ (95\% CI $0.84-3.13$ ) for major bleeding incidents, but the need for further clinical trials was underlined. These values prove that cessation of the NOACs is associated with low risk of incidents, making it a viable attitude for patients who need bleeding dental procedures [28-31]. On the other hand, the cardiologist could decide against the cessation of the NOACs, and the dental practitioner must take preventive measures against the bleeding complications that may occur. In order to reduce the bleeding risk, the interventions can be planned at a time interval of 12 hours after the last dosage of dabigatran and apixaban. Furthermore, using a local anaesthesia solution containing vasoconstrictors is indicated and may help in the reduction of peri-procedural and postoperative bleeding [15,31]. The literature data does not provide clear indications about the cessation or the continuation of the anticoagulant therapy during dental procedures. This is due, in part, to the insufficient large clinical prospective cohort studies [20]. However, the available literature suggests some indications based on small prospective or retrospective studies, case reports or series. As seen in the complex analysis of the eligible articles for the present study, most of the authors agree that the therapeutic approach regarding NOACs 
can be decided according to the complexity of dental procedure. All procedures must be as non-traumatic as possible and local haemostatic measures, such as suture and haemostatic sponges, should be applied. The dental practitioner must be aware of the bleeding complications that may occur and of the correct approach for treating them. In the case presented in our paper, even though local haemostatic methods were applied, the NOAC was not ceased and bleeding episodes continued to occur in the days following the intervention and were associated with the administration of the anticoagulant.

However, a thorough analysis of the patient's general pathology may reveal other factors contributing to the postinterventional complications. The teleangiectatic lesions revealed at the exooral examination could be relevant, since the literature supports their association with the alteration of the coagulation process and coagulation disorders [32]. Thus, a general predisposition to bleeding, apart from the one caused by Rivaroxaban, should be taken into consideration. Another indicator of the general predisposition for bleeding could be the gingival bleeding during treatment with Dabigatran, which was replaced with another NOAC, Rivaroxaban. The insufficient data on the use of NOACs points to the need for further clinical studies and for more accurate clinical guidelines, taking into consideration the relatively high incidence of postoperative bleeding complications, compared with the traditional anticoagulants $[6,8,9,13,19,20,22-24]$.

\section{Conclusion}

In conclusion, prior to surgical interventions in the oral cavity, the dental practitioner must revise the treatment with new generation oral anticoagulants. The data available in the literature mainly indicates when the anticoagulant therapy should be ceased. This decision must be taken with the cardiologist, who are able to evaluate the thromboembolic risk of patients. Moreover, the treatment plan proposed by the dental practitioner must be critically analysed by the cardiologist and a correct timeframe and attitude toward bleeding procedures must be indicated. However, further clinical research is needed in order to provide exact guidelines. Even when taking what seems to be the right decision regarding the cessation or non-cessation of the NOACs according to literature, bleeding complications might still occur, as proven by the case presented here.

\section{Conflict of Interest Statement}

The authors declare no conflicts of interest with respect to the authorship and/or publication of this article.

\section{Acknowledgment}

Ilea Aranka and Andrei Vlad have equal contribution as first authors of this article. This study was financed partially by the COFUND-ERA-HDHL ERANET Project, European and International Cooperation- Subprogram 3.2-Horizon 2020, PNCDI III Program - Biomarkers for Nutrition and Health-"Innovative technological approaches for validation of salivary AGEs as novel biomarkers in evaluation of risk factors in diet-related diseases", grant no 25/1.09.2017.

\section{References}

1. Galindo LM, Bagán JV (2015) Apixaban and oral implications. J Clin Exp Dent 7(4): e528-534.

2. Ingrasciotta $\mathrm{Y}$, Crisafulli S, Pizzimenti V, Marcianò I, Mancuso A, et al. (2018) Pharmacokinetics of new oral anticoagulants: implications for use in routine care. Expert Opin Drug Metab Toxicol 14(10):1057-1069.

3. Kandrotas RJ (1992) Heparin pharmacokinetics and pharmacodynamics. Clin Pharmacokinet 22(5): 359-374.

4. Johnston S (2016) An evidence summary of the management of patients taking direct oral anticoagulants (DOACs) undergoing dental surgery. Int J Oral Maxillofac Surg 45(5): 618-630.

5. Shearer MJ, Fu X, Booth SL (2012) Vitamin K nutrition, metabolism and requirements: Current concepts and future research. Adv Nutr 3(2): 182-195.

6. Thean D, Alberghini M (2016) Anticoagulant therapy and its impact on dental patients: A review. Aust Dent J 61(2): 149-156.

7. Moreno GG, Cejas FE, Salvatierra AA, de Carlos F, Ruiz RA, et al. (2018) Dental implant surgery in patients in treatment by dabigatran. Clin Oral Implants Res 29(6): 644-648.

8. Elad S, Marshall J, Meyerowitz C, Connolly G (2016) Novel anticoagulants: General overview and practical considerations for dental practitioners. Oral Dis 22(1): 23-32.

9. Curto A, Curto D, Sanchez J (2017) Managing patients taking edoxaban in dentistry. J Clin Exp Dent 9(2): e308-311.

10. Olaiya A, Lurie B, Watt B, McDonald L, Greaves M, et al. (2016) An observational study of direct oral anticoagulant awareness indicating inadequate recognition with potential for patient harm. J Thromb Haemost JTH 14(5): 987-990.

11. Miranda M, Martinez LS, Franco R, Forte V, Barlattani A, et al. (2016) Differences between warfarin and new oral anticoagulants in dental clinical practice. Oral Implantol 9(3): 151-156.

12. Chaudhry S, Jaiswal R, Sachdeva S (2016) Dental considerations in cardiovascular patients: A practical perspective. Indian Heart J 68(4): 572-575.

13. Firriolo FJ, Hupp WS (2012) Beyond warfarin: The new generation of oral anticoagulants and their implications for the management of dental patients. Oral Surg Oral Med Oral Pathol Oral Radiol 113(4): 431-441.

14. Breik O, Cheng A, Sambrook P, Goss A (2014) Protocol in managing oral surgical patients taking dabigatran. Aust Dent J 59(3): 296-301.

15. Moreno GG, Salvatierra AA, Cejas FE, Ruiz RA, Markovic A, et al. (2016) Dental implant surgery in patients in treatment with the anticoagulant oral rivaroxaban. Clin Oral Implants Res 27(6): 730-733.

16. Hanken H, Gröbe A, Heiland M, Smeets R, Kluwe L, et al. (2016) Postoperative bleeding risk for oral surgery under continued rivaroxaban anticoagulant therapy. Clin Oral Investig 20(6): 1279-1282.

17. Nathwani S, Wanis C (2017) Novel oral anticoagulants and exodontia: The evidence. Br Dent J 222(8): 623-628.

18. Dézsi CA, Dézsi BB, Dézsi AD (2017) Management of dental patients receiving antiplatelet therapy or chronic oral anticoagulation: A review of the latest evidence. Eur J Gen Pract 23(1): 196-201.

19. Lababidi E, Breik O, Savage J, Engelbrecht H, Kumar R, et al. (2018) Assessing an oral surgery specific protocol for patients on direct oral anticoagulants: a retrospective controlled cohort study. Int J Oral Maxillofac Surg 47(7): 940-946. 
20. Costantinides F, Rizzo R, Pascazio L, Maglione M (2016) Managing patients taking novel oral anticoagulants (NOAs) in dentistry: A discussion paper on clinical implications. BMC Oral Health 16: 5.

21. Sánchez SV, Ripollés de Ramón J, Yurrita CL, Checa VI, Ruiz CC, et al. (2017) New horizons in anticoagulation: Direct oral anticoagulants and their implications in oral surgery. Med Oral Patol Oral Cirugia Bucal 22(5): e601-608.

22. Hassona Y, Malamos D, Shaqman M, Baqain Z, Scully C (2018) Management of dental patients taking direct oral anticoagulants: Dabigatran. Oral Dis 24(1-2): 228-232.

23. Romond KK, Miller CS, Henry RG (2013) Dental management considerations for a patient taking dabigatran etexilate: a case report. Oral Surg Oral Med Oral Pathol Oral Radiol 116(3): e191-195.

24. Davis C, Robertson C, Shivakumar S, Lee M (2013) Implications of dabigatran, a direct thrombin inhibitor, for oral surgery practice. J Can Dent Assoc 79: d74.

25. Miclotte I, Vanhaverbeke M, Agbaje JO, Legrand P, Vanassche T, et al. (2017) Pragmatic approach to manage new oral anticoagulants in patients undergoing dental extractions: a prospective case-control study. Clin Oral Investig 21(7): 2183-2188.

26. Kim C, Dam C, Jeong J, Kwak EJ, Park W (2017) Delayed bleeding after implant surgery in patients taking novel oral anticoagulants: a case report. J Dent Anesth Pain Med 17(2): 143-147.
27. Fortier K, Shroff D, Reebye UN (2018) Review: An overview and analysis of novel oral anticoagulants and their dental implications. Gerodontology 35(2): 78-86.

28. Shaw JR, Woodfine JD, Douketis J, Schulman S, Carrier M (2018) Perioperative interruption of direct oral anticoagulants in patients with atrial fibrillation: A systematic review and meta-analysis. Res Pract Thromb Haemost 2(2): 282-290.

29. Shaw J, de Wit C, Le Gal G, Carrier M (2017) Thrombotic and bleeding outcomes following perioperative interruption of direct oral anticoagulants in patients with venous thromboembolic disease. J Thromb Haemost JTH 15(5): 925-930.

30. Clark NP, Witt DM, Davies LE, Saito EM, McCool KH, et al. (2015) Bleeding, recurrent venous thromboembolism and mortality risks during warfarin interruption for invasive procedures. JAMA Intern Med 175(7): 1163-1168.

31. Tsolka P (2014) Dental procedures in patients with atrial fibrillation and new oral anticoagulants. Arrhythmia Electrophysiol Rev 3(2): 85-89.

32. Haitjema T, Westermann CJ, Overtoom TT, Timmer R, Disch F, et al. (1996) Hereditary hemorrhagic telangiectasia (Osler-Weber-Rendu disease): new insights in pathogenesis, complications and treatment. Arch Intern Med 156(7): 714-719. 